\title{
Educação, saúde e modos de inscrever uma forma de maternidade nos corpos femininos
}

Dagmar Estermann Meyer ${ }^{l}$

\begin{abstract}
Resumo: Discuto, neste trabalho, representações e identidades de mãe que vêm sendo produzidas e/ou veiculadas no âmbito de programas de educação em saúde voltados à população materno-infantil. Utilizo a abordagem da análise cultural, tal como esta vem sendo desenvolvida pelos Estudos Culturais e de Gênero, para analisar tais programas de saúde, concebendo-os como instâncias pedagógicas que produzem, ressignificam e veiculam determinados modos de conhecer, viver e valorar a maternidade na contempora-neidade. Examino modos pelos quais a "pedagogia" engendrada pela teia de discursos e de poderes que institui tais programas atua, ressignificando a relação mãe-filho para inscrever o corpo materno em um poderoso regime de vigilância e regulação. Tal estratégia de poder incorpora ao exercício da maternidade atributos relacionados com a resolução de uma vasta gama de problemas que as sociedades globalizadas produzem e não conseguem resolver. Argumento que na contem-poraneidade vem-se engendrando uma nova politização da maternidade, na qual programas de atenção à saúde estão bastante implicados
\end{abstract}

Palavras-chave: Estudos Culturais e de Gênero, Políticas de Corpo e Saúde, Representação Cultural, Produção de Maternidade.

\section{A "localização" do texto e de suas questões}

.... [e Deus disse:] Quando eu criei a mulher, tinha de fazer algo muito especial. (...) Dei a ela uma imensa força interior, para que pudesse suportar as dores da maternidade (...) Dei-lhe a fortaleza que lhe permite continuar sempre a cuidar da sua família, sem se queixar, apesar das enfermidades e do cansaço, até mesmo quando outros entregam os pontos!

1 Doutora em Educação. Professora Adjunta na Faculdade de Educação da UFRGS e atual coordenadora do GEERGE (Grupo de Estudos de Educação e Relações de Gênero), na mesma instituição.

2 Excerto de um texto, sem autoria, que circulou pelas listas de endereços eletrônicos (emails) no período das comemorações dedicadas ao dia das mães, em maio de

Movimento Porto Alegre, v.9, n. 3, p.33-58, set./dez. de 2003 
A epígrafe com que inicio este texto reúne alguns dos enunciados sobre maternidade que circulam, cotidiana e recorrentemente, em múltiplas instâncias e artefatos de nossa cultura. Apresentados como se fizessem parte da natureza das mulheres que se tornam mães, os atributos e valores que tais enunciados instituem já fazem parte do senso comum. Além disso, ou exatamente por isso, eles também norteiam muitos dos processos educativos no interior dos quais nos tornamos mulheres e homens e/ou mães e pais de determinados tipos e sua força reside, justamente, nas múltiplas, sutis e sempre renovadas possibilidades de sua repetição. Educação e Saúde são dois dos campos de conhecimentos e práticas que produzem, atualizam e repetem, incessantemente, o que a mãe é ou deve ser e sua "autoridade científica" constitui uma importante estratégia de naturalização e universalização de tais definições.

Na confluência desses campos, vários estudos têm enfatizado que as mulheres seguem sendo as maiores freqüentadoras e /ou usuárias da rede de assistência à saúde. Elas continuam sendo interpeladas e responsabilizadas, também de forma central, pelos programas de promoção da saúde e de prevenção de doenças, ou daqueles que se guiam por imperativos sociais tais como o "toda criança na escola". Isso se pode ver, de modo exemplar, nos desdobramentos mais recentes dos programas de Incentivo ao Aleitamento Materno, prevenção do HIV/AIDS bem como em todos os programas que compõem a chamada "rede. de apoio social", implementada pelo governo FHC, e onde se integram, e. g., o Bolsa Escola, Família na Escola, Bolsa Alimentação, etc.

Apesar dos inegáveis avanços referentes à condição de saúde de mulheres e crianças e aos níveis de escolarização básica, promovidos por esses programas educativos e de atenção à saúde materno-infantil, através da atuação de várias instituições governamentais e da sociedade civil, estudos como os que vimos desenvolvendo, recentemente, em algumas linhas de pesquisa no PPG- EDU da UFRGS (e.g. Meyer, 2002; Duro, 2002; Klein, 2003; Santos, 2002; Souza e cols., 2002 e Marcello, 2002), dentre outros produzidos nacional e internacionalmente, permitem argumentar que a redução da noção de mulher às noções de mãe e de cuidadora qualificada dos componentes do núcleo familiar, e/ ou de saúde da mulher à dimensão de saúde do aparelho reprodutor feminino, é um processo que vem ganhando novas "roupagens" e dimensões em alguns desses programas. 
Em minhas investigações, ${ }^{3}$ particularmente, descrevo e analiso representações de mulher-mãe produzidas e/ou veiculadas no âmbito de políticas, fundamentalmente educativas, voltadas à promoção da saúde e à prevenção de doenças desse segmento priorizado em termos de políticas públicas de saúde que é, genericamente, definido como materno-infantil, entendendo essas políticas (e os programas delas decorrentes) como instâncias de produção de corpos e identidades sociais e culturais. Utilizando a abordagem da análise cultural, tal como esta vem sendo desenvolvida pelos Estudos Culturais e de Gênero, que se aproximam do Pós-Estruturalismo, descrevo e analiso, neste artigo, documentos referentes a um desses programas de saúde (o Programa Nacional de Incentivo ao aleitamento Materno) para, com e a partir dessa análise, defender o argumento de que, na contemporaneidade, vem-se engendrando uma nova politização da maternidade.

\section{Educação, saúde e maternidade: uma abordagem feminista e cultural}

Os estudos antes citados vêm permitindo delinear, nas representações de mulher-mãe que programas educacionais, de saúde e a mídia produzem ou veiculam, elementos importantes de representações produzidas nos séculos XVIII e XIX, nas culturas européias ocidentais (cf., e. g. Meyer, 2000a e Meyer; Oliveira, 2003). Ao mesmo tempo, essas representações parecem incorporar e inscrever, no corpo feminino e na maternidade, "novos" e conflitantes "atributos" derivados tanto das lutas de movimentos sociais como o feminismo e os movimentos em prol dos direitos humanos, quanto da influência de um leque cada vez maior de conhecimentos, cientificamente autorizados a definir e prescrever modos mais adequados de cuidar e se relacionar com a infância, dentre os quais se destacam a Medicina, a

\footnotetext{
3 Trata-se de duas pesquisas, uma concluída e outra em andamento. A primeira, já concluída, intitulada Mulher perfeita tem que ter [mamas e] uma barriguinha. Educação, saúde e produção de identidades maternas, foi desenvolvida com apoio do $\mathrm{CNPq}$ e da FAPERGS e com a colaboração das bolsistas Silvana Praça Liesenfeld e Anelise Schutz, do PIBIC-UFRGS/CNPq, no período de março de 2000 a dezembro de 2002 . A segunda, em andamento, intituladaa Educar e assistir corpos grávidos para gerar e criar seres humanos "saudáveis". Educação, saúde e constituição de sujeitos "de direito" e "de risco" vem sendo desenvolvida desde março de 2003, com apoio do programa de Bolsa de Produtividade em Pesquisa do CNPq e envolve a bolsista Letícia Fernandes, do PIBIC/CNPq-UFRGS.
}

Movimento Porto Alegre, v.9, n. 3, p.33-58, set./dez. de 2003 
Psicanálise, a Psicologia, o Direito e a Pedagogia. Repercutem também, nesses sistemas de representação, efeitos das profundas e abrangentes transformações sociais, econômicas e culturais desencadeadas pelo neoliberalismo e pela globalização.

Como enfatizam vários autores/as (e.g. Dean,1999; Petersen, 1997 e Nettleton, 1997), a racionalidade neo-liberal caracteriza-se, dentre outras coisas, por conceber a vida e o indivíduo como empreendimentos infinitamente "aperfeiçoáveis" e pressupor que todos os indivíduos têm o direito e, sobretudo, o dever de manter, gerir e potencializar o seu próprio bem-estar. Este indivíduo é concebido como um sujeito autônomo, capaz de se autogovernar mais e melhor na medida em que se capacita (ou é capacitado) para fazer escolhas e responsabilizar-se por elas. E tais escolhas estão, hoje, conectadas ao acesso e ao domínio de um amplo leque de informações, "desdobráveis" em conjuntos cada vez mais complexos, abrangentes e diversos de necessidades e possibilidades de viver de forma competente e saudável. Ou seja, o pressuposto de que o indivíduo pode e deve aperfeiçoar cada vez mais sua forma de viver, seu corpo ou sua saúde implica, também, em colocar, na esfera da pessoa, a responsabilidade pela alocação dos meios e recursos necessários para a consecução desse "projeto" de vida e saúde.

A globalização, centrada como está no ideal do livre mercado, na informação e na tecnologia, encontra-se profundamente imbricada com esta racionalidade da modernidade tardia e seus reflexos, embora sentidos em quase todos os países, se traduzem como benefícios diretos para pouco mais de um terço da população mundial. Os dois terços restantes, localizáveis em todos os continentes, são afetados negativamente por esse processo:

A busca obsessiva da eficiência faz aumentar continuamente o número dos que são marginalizados, inclusive nos países desenvolvidos. Assim como a mecanização da agricultura provocou o êxodo rural, inflando as cidades e suas periferias, a racionalização atual da produção empurra os pobres ainda mais para as margens da economia, que não coincidem necessariamente com as periferias urbanas. Com a informatização crescente da indústria e dos serviços, o trabalho não-especializado torna-se supérfluo e o desemprego, estrutural. A mão-de-obra barata, ainda imprescindivel na produção, é recrutada fora do espaço nacional, pelas filiais de grandes corporações instaladas no exterior, ou na acolhida politicamente relutante - de estrangeiros imigrados. Nas sociedades ricas ou emergentes, o desmonte da previdência pública, alegadamente necessário à gestão estatal eficaz, transforma a exclusão em contrapartida aceitável da competitividade nacional Nas sociedades pobres, a atração de investimentos externos é fator de 
vida e morte. Os atrativos não são, contudo, suficientes para garantir a permanência de capitais voláteis, que podem sair de qualquer país, do dia para a noite, em função de problemas observados em outras partes do mundo. Como paliativo aos efeitos colaterais da globalização, transfere-se à iniciativa privada è às organizações da sociedade civil [ou ao individuo] a responsabilidade pela administração do social. Estas, não obstante, funcionam apenas na escala de seus meios e de seu humanitarismo [ou de seus interesses]. Abandona-se, assim, a concepção dos direitos econômico-sociais (Lindgren Alves, 2002, p. 4).

Quando se buscam, então, delimitar efeitos desses discursos e processos nas representações de maternidade produzidas e/ou veiculadas nas políticas públicas que venho examinando, chama atenção a ampliação e complexificação do leque de condutas, modos de cuidar e modos de sentir que dizem respeito a uma relação mãefilho "normal" e "natural", as quais são apresentadas como sendo indispensáveis para o processo de desenvolvimento físico e, principalmente, emocional de crianças que devem tornar-se adultos produtivos, equilibrados e "saudáveis". Chama atenção, ainda, a incorporação de uma "linguagem do risco" (cf. Spink, 2001) com e através da qual determinados grupos de mulheres são classificados e valorados, crescentemente, como "mães de risco" e, por conseqüência, transformados em sujeitos-alvo de práticas assistenciais, educativas e de controle mais sistemáticas e estandartizadas.

O exame de tais representações, considerando-se, exatamente, o contexto das sociedades neoliberais globalizadas, vem-me permitindo perceber que a noção de indivíduo mulher-mãe, ainda supõe, ou supõe com força renovada, a existência de um ser que incorpora e se desfaz em múltiplos - a mãe e sua família e, mais especificamente, a mãe e seus filhos. Nesse contexto, gerar e criar filhos "equilibrados e saudáveis" passa a ser social e culturalmente definido, também, como um "projeto" de vida, responsabilidade individual de cada mulher que se torna mãe, independentemente das condições sociais em que essa mulher vive e dos problemas que ela enfrenta, e é a isso que venho me referindo como uma nova politização da maternidade.

Corroborando esse argumento, Aminatta Forna (1999, p.21), ao problematizar a ênfase contemporânea em um determinado estilo de maternidade, adverte:

Na década de 60, as feministas repudiaram a visão super romanceada da maternidade, identificando nela os laços de seda da opressão. (...). Um descuido por parte do movimento feminista como um todo foi ignorar a maternidade a partir de então, acreditando que, se toda a energia política fosse dedicada a aumentar as 
possibilidades de escolha profissional das mulheres no sentido de alcançar a independência econômica, a maternidade acharia um modo de se resolver. (...) Na verdade, a história de como o feminismo deve lidar com as questões em torno da maternidade está apenas começando.

Para mim, a atualidade e a pertinência dessa problematização se colocou quando comecei a me deparar, sistematicamente, nos documentos que vinha analisando, com um conjunto disperso, porém recorrente de enunciados que atribuem o desenvolvimento físico, cognitivo e afetivo saudável do feto e da criança a sentimentos, comportamentos, formas de cuidar e se relacionar com o feto/criança que, apesar das inovações tecnológicas e das conquistas dos movimentos feministas, transformaram o exercício da maternidade, na contemporaneidade, em uma tarefa extremamente difícil e abrangente. A prática do aleitamento materno, tal como esta é concebida e recomendada hoje pode, a meu ver, ser tomada como um exemplo emblemático desse processo.

A autora (1999, p. 15) desenvolve o argumento de que a criação dos filhos segue sendo uma tarefa exclusivamente feminina e que, hoje, ela já começa antes do momento da concepção:

Espera-se que a futura mãe se abstenha de café, chá, álcool, fumo (inclusive passivo), determinados tipos de alimentos industrializados, estresse, excesso de exercícios (...) Durante a gravidez, o desenvolvimento do bebê e todos os aspectos do comportamento dela são minuciosamente monitorados pelos serviços de saúde. (...) Para o melhor e para o pior, hoje, as responsabilidades da mãe dobraram: a estabilidade emocional e o desenvolvimento cognitivo e psicológico dos filhos também estão a seu encargo. (...) As mães são bombardeadas com mais informaçôes do que conseguem absorver e o conselho é sempre apresentado como o "melhor para o seu bebê", porém envolve vários outros interesses (ou dificuldades) sociais, politicos e culturais.

E é exatamente por concordar com ela que penso que estudos que se proponham a articular educação, saúde e gênero podem contribuir para delimitar, de forma mais ampla, as redes de poder que se colocam em movimento com determinadas ênfases educativas, instrumentos de diagnóstico e modos de assistir e monitorar mulheres-mães, que vêm sendo utilizados no contexto destes e de outros programas de saúde, na atualidade. E, para além disso, penso que a problematização da maternidade, tal como esta vem sendo dimensionada hoje, se recoloca como um tema central para os Estudos de Gênero, também no Brasil contemporâneo. 
No âmbito dos movimentos feministas, a politização da maternidade pode ser localizada no contexto de uma problematização mais ampla desencadeada no bojo da chamada segunda onda do feminismo, um movimento teórico, social e político que teve um profundo impacto sobre os modos pelos quais o sujeito e a identidade foram (são) conceptualizados na modernidade. Questionando a clássica distinção entre o "privado" e o "público" o feminismo, com o slogan de que "o pessoal é político", colocou em debate, nas arenas acadêmica e política, temas relacionados com a família, a sexualidade, o trabalho doméstico, a divisão sexual do trabalho, o cuidado com as crianças como capacidade inata da mulher, que antes não eram ai considerados. Com a (hoje) antológica frase de Simone de Beauvoir (1980) de que não nascemos mulheres, mas nos tornamos mulheres, o feminismo também começou a colocar em xeque o pressuposto biologicista que permitia inscrever o feminino no sexo anatômico e passou a prestar atenção nos modos pelos quais, no âmbito do social e da cultura, somos produzidos e formados como sujeitos de gênero. Um dos elementos centrais dessas problematizações foi, justamente, o determinismo biológico com o qual se traduzia a maternidade como sendo tanto um instinto quanto o destino natural da mulher.

A maternidade passava, a partir de então, a ser compreendida e discutida como sendo uma dimensão profundamente implicada com os processos de dominação/subordinação que regiam as relações entre os sexos, nas sociedades ocidentais. Lucila Scavone (2001), ao discutir as imbricações entre maternidade e feminismo, sintetiza três vertentes que poderiam caracterizar as discussões realizadas em torno de tal relação: uma primeira, em que a recusa da maternidade foi apresentada, por feministas radicais como Sulamita Firestone, como o principal instrumento para subverter a dominação masculina; uma segunda, em que a maternidade passaria a ser teorizada como um poder insubstituível das mulheres, o que caracteriza, por exemplo, o chamado feminismo da diferença de Luce Irigaray; e uma terceira, que poderia ser chamada de feminismo pós-estruturalista, no qual se tomam como focos de análise, exatamente, os mecanismos e as estratégias de poder/saber que, nas culturas ocidentais modernas, permitem definir e apresentar a maternidade como se esta fosse uma essência, monolítica e ahistórica, inscrita na anatomia, fisiologia e/ou psique da mulher.

Movimento Porto Alegre, v.9, n. 3, p.33-58, set./dez. de 2003 
Continuamos convivendo, ainda hoje, no campo dos Estudos Feministas, com estas e várias outras possibilidades de abordar a maternidade e o meu trabalho se "localiza" exatamente nessa terceira vertente, que se organizou em torno do conceito de gênero, com o qual estudiosas anglo-saxãs passariam a focalizar, desde os anos 70, o caráter fundamentalmente social e lingüístico das distinções percebidas entre homens e mulheres (cf. Scott, 1995 e Louro, 1997).

Importantes mudanças epistemológicas decorrem da adoção do conceito de gênero, na perspectiva em que este passaria a ser utilizado a partir de então. Gênero aponta para a compreensão de que, ao longo da vida, através das mais diversas instituições e práticas sociais, nos constituímos como homens e mulheres, num processo que nunca está finalizado ou completo. Além disso, ele sugere que, como nascemos e vivemos em tempos, lugares e circunstâncias específicos, há muitas formas de viver e de constituir a feminilidade e a masculinidade. Com esse conceito pretende-se, ainda, enfatizar o caráter plural e multifacetado da construção social e histórica de sujeitos femininos e masculinos - uma pluralidade que se expressa pela articulação com muitas outras dimensões sociais, tais como classe, raça/etnia, geração, religião, nacionalidade. Além destas, o conceito introduziu ainda outras mudanças significativas no campo dos estudos feministas, uma vez que ele sinaliza não apenas para as mulheres, nem mesmo toma exclusivamente suas condições de vida como objeto de análise, mas, em vez disso, traz implícita a idéia de que as análises e as intervenções empreendidas devem considerar as relações entre mulheres e homens e as muitas formas sociais e culturais que os constituem como "sujeitos de gênero".

Um outro desdobramento importante desse conceito é a proposição de afastar-se de análises que repousam sobre uma idéia reduzida de papéis/funções de mulher e de homem, deslocando-se para uma abordagem muito mais ampla que nos leva, também, a admitir que as próprias instituições, os campos de saber, os símbolos, as normas, as leis de uma sociedade são constituídas pelas representações de feminino e de masculino e expressam e reproduzem essas representações. Nessa perspectiva, deixa-se de enfocar somente os processos pelos quais seres humanos se transformam em mulheres e homens e em mães e pais de um determinado tipo, para considerar que o gênero institui e atravessa o social e a cultura em que estamos inseridos. 
É com este enfoque que o conceito, em sua confluência com os Estudos Culturais, ${ }^{4}$ é utilizado como suporte para compreender e problematizar processos de produção de diferenças e desigualdades sociais que são colocados em ação na relação entre educação e saúde (por exemplo, diferenças de classe, gênero, raça, geração), sobretudo porque podemos perceber como esses processos funcionam, posicionando mulheres-mães em torno de eixos como saudável/doente ou normal/patológico ou, ainda, norma/risco, com base nos conhecimentos que dão sustentação às práticas desenvolvidas nesses campos.

Essa é, portanto, uma abordagem cuja ênfase está colocada na descrição e na análise dos mecanismos pelos quais o poder conecta aquelas dimensões da cultura em que se define o que é maternidade com conhecimentos educacionais, médicos, psicológicos, jurídicos, etc. Por isso, ela possibilita romper a suposta linearidade e homogeneidade de representações de maternidade, definidas como naturais e universais, para visibilizar e explorar os conflitos que as constituem e atravessam. Tal abordagem permite, ainda, tratar os programas de saúde como instâncias que incorporam, ressignificam e veiculam, de forma ativa, estas (e outras) representações e identidades culturais.

Representação ${ }^{5}$ refere-se, neste texto, às práticas de significação lingüística e cultural e aos sistemas simbólicos através dos quais os significados de maternidade - que permitem às mulheres entender suas experiências e definir o que elas devem ser, fazer e sentir enquanto mães - são construídos. Está implícita, aqui, a importante premissa de que características anatômicas como ter ou não ter mamas e útero, funções biológicas como a capacidade de engravidar ou de produzir e secretar leite, comportamentos e sentimentos de doação, cuidado ou amor ilimitados, usualmente inscritos no corpo feminino ou colados à maternidade não têm, em si mesmos, qualquer significado fixo, final e verdadeiro, mas são produzidos e passam a significar algo específico no interior de culturas específicas.

Entendida como um sistema de significação lingüística e cultural, a representação - e as identidades que ela produz e

4 Para uma leitura mais aprofundada desse campo dos Estudos Culturais, ver, e.g. Hall, 1997; Woodward, 1997; Silva, 2000 e Meyer, 2000b.

5 A partir daqui, o texto incorpora, com modificações e aprofundamentos, partes de dois textos que escrevi e/ou publiquei no decorrer da pesquisa, quais sejam: Meyer, 2000a e Meyer, 2002

Movimento Porto Alegre, v.9, n. 3, p.33-58, set./dez. de 2003 
coloca em circulação - incorpora, também, todas as características de indeterminação, ambigüidade e instabilidade atribuídas à linguagem na perspectiva pós-estruturalista. Pode-se dizer, então, que as representações que significam e inscrevem a maternidade no corpo (e na "alma"!) da mulher, em diferentes espaços e tempos, são, ao mesmo tempo, incapazes de fixar nele, de uma vez para sempre, um conjunto verdadeiro, definido e homogêneo de marcas/sentidos. Para além disso, todas as representações de mulher e/ou maternidade produzem sentidos que funcionam competindo entre si, deslocando, acentuando ou suprimindo convergências, conflitos e divergências entre diferentes discursos e identidades; mas são algumas delas que, dentro de determinadas configurações de poder, acabam se revestindo de autoridade científica e/ou se transformando em senso comum, a tal ponto que deixamos de reconhecê-las como representações. É assim que uma delas passa a funcionar, num determinado contexto sóciohistórico e cultural, como sendo a melhor ou a verdadeira maternidade, aquela que se transforma em referência das ações assistenciais e educativas em saúde e a partir da qual as outras maternidades são classificadas e valoradas como sendo maternidades de risco ou maternidades desviantes.

As práticas de significação e os processos simbólicos, através dos quais os sentidos de maternidade são construídos ou veiculados exercem, pois, o poder de nomear, descrever, classificar, identificar e diferenciar, por exemplo, jeitos de ser- mulher e mãe; o poder de incluir, excluir e definir corpos, comportamentos, grupos e/ou mulheres individuais e, assim, demarcar os seus lugares sociais.

Vistos desta forma, os sistemas de representação, quando posicionam seres humanos como mulheres, mães e/ou nutrizes e cuidadoras de diferentes tipos ou, ao proporcionarem respostas que possibilitam a elas entender aquilo que são/devem fazer enquanto mães ou, ainda, ao operarem a equivalência entre o ser mãe e a prática da amamentação, ou entre maternidade e amor desmedido ou abnegado, conformam corpos e identidades. E isso implica dizer que os processos de definição de maternidades normais, de risco e desviantes, da mãe responsável ou relapsa, de vínculos mãe-filho adequados ou inadequados, que ocorrem dentro ou no entorno dos programas de saúde, e que direcionam de um determinado modo as ações educativas que eles propõem, têm efeitos muito concretos nas vidas das pessoas 
e dos grupos de mulheres que neles são definidos, posicionados e mobilizados.

É importante dizer que, nesta perspectiva de análise não está em questão fazer uma distinção entre representação e aquilo que está fora ou é anterior a ela. Não se trata, também, de pesquisar se os programas de saúde, tal como estes vêm sendo concebidos e implementados, são bons ou não para o binômio mãe-filho; nem se pretende, com ela, negar o valor de verdade de outros estudos que abordam tais programas, demonstrando a redução de taxas de morbimortalidade infantil e materna; não se tem como objetivo contrapor a tais estudos outros dados mais verdadeiros ou mais próximos do real que então permitiriam a mim, desde essa perspectiva teórica privilegiada, descrever a verdadeira natureza (ou a natureza conspiratória!) destes programas e dos interesses imbricados nas campanhas em prol da saúde da materno-infantil.

Trata-se, sim, de investir em um outro viés de análise, problematizando alguns dos modos pelos quais a "materialidade" da maternidade se torna inteligível, se expressa e se concretiza em representações (imagens, textos, áreas de conhecimento, práticas de assistência, corpos) que definem e regulam o ser mãe nas ações de formação profissional e de educação em saúde envolvidas com a promoção da saúde da mulher e da criança. Ou seja, busca-se com essa perspectiva discutir o que vem "junto com" e, portanto, institui e atravessa tais saberes e práticas que, no final das contas, ao nos transformarem (ou não) em um determinado tipo de mãe, têm efeitos de poder muito concretos em nossas vidas.

\section{Amamentar: um imperativo contemporâneo posto às mulheres para garantir a sobrevivência global? $^{6}$}

A atual política de incentivo ao aleitamento materno - que tomo como exemplo para discutir a politização da maternidade a que me refiro no texto - introduziu uma significativa ruptura nos saberes norteadores das prescrições e recomendações médicas acerca da amamentação utilizados até o início dos anos 80.

6 Sub-título inspirado em Law, 2000, p. 435.

Movimento Porto Alegre, v.9, n. 3, p.33-58, set./dez. de 2003 
Tal ruptura implica, a meu ver, importantes modificações nas formas de governar a vida das mulheres, o exercício da maternidade e a amamentação.

Trata-se, dentre outras coisas, de substituir o modelo alemão então vigente na puericultura brasileira pelo regime da livre demanda. O modelo alemão postulava que

o recém-nascido deveria ser submetido a um importante regime de disciplina e condicionamento que, traduzido em termos de amamentação, significava mamar de três em três horas e não mais do que 15 minutos em cada mama (Almeida, 1999, p. 78).

A livre demanda, por sua vez, passa a ser definida pelo imperativo de que

Todas as mulheres devem estar habilitadas a praticar o aleitamento materno exclusivo, e todos os bebês devem ser amamentados exclusivamente com leite materno desde o nascimento até os quatro a seis meses. Após esse periodo, as crianças devem continuar sendo amamentadas ao peito, juntamente com alimentos complementares, até os dois anos ou mais. (Manual, 1993, p. 3).

Essa é a meta proclamada (e não alcançada), para os anos noventa, de um dos mais significativos desdobramentos dessa busca pela eficiência e eficácia das políticas de incentivo à amamentação, no Brasil: a adesão do governo e de várias organizações da sociedade civil à Iniciativa Hospital Amigo da Criança (IHAC):

Um esforço mundial, patrocinado principalmente pela OMS e pelo UNICEF, para promover, proteger e apoiar o aleitamento materno, mediante a adoção, pelos hospitais, dos 'Dez passos para o incentivo do aleitamento materno'(Cf. site ${ }^{7}$ Amamentação on Line).

O Brasil aderiu a esta iniciativa, denominada de "código de conduta", em agosto de 1990 e foi um dos doze países escolhidos para liderar sua implementação. A IHAC delineia, ainda segundo o texto divulgado nesse site, um importante papel de apoio que os hospitais podem desempenhar a fim de tornar o aleitamento materno uma prática universalmente adotada nas ma-ternidades, contribuindo significativamente para a saúde e o desenvolvimento de milhões de bebês. O que o site não explicita é que a credencial Hospital Amigo da Criança, conferida pelo UNICEF após uma rigorosa avaliação do processo de implanta-

7 http://www.aleitamento.org.br/oqueeihac.htm

Movimento Porto Alegre, v.9, n. 3, p.33-58, set./dez. de 2003 
ção dos "Dez passos", representa um incremento próximo de $10 \%$ no orçamento anual da instituição para o atendimento especializado em obstetrícia (cf. ZH de 25/07/2000). Recursos esses tão necessários e significativos, em um contexto de falência e desmantelamento da rede de serviços de saúde públicos e /ou vinculados ao Sistema Único de Saúde, que o mesmo jornal informa:

com o objetivo de conquistar a adesão de um maior número de hospitais à IHAC, será realizado hoje e amanhã, em Porto Alegre [RS/Brasil], curso especifico para gestores hospitalares. Organizado pela Secretaria da Saúde do Estado (...) (ZH, $5 / 9 / 2000)$.

Os aspectos mais enfatizados nos materiais educativos voltados ao incentivo do aleitamento materno envolvem explicações acerca das vantagens dessa prática para a criança e para a mãe e "dicas", tanto para amamentar corretamente quanto para cuidar de si (de forma a garantir a produção de leite) e, em especial, das mamas durante o período da amamentação. Isso se expressa em frases como "desde o início da gravidez a mulher deve preparar o seio para a amamentação" ou "o apoio do marido e da família é muito importante para o sucesso do aleitamento" ou, ainda, "não existe nenhum leite igual ao leite materno" (folheto 1). ${ }^{8}$ Tais elementos do discurso são exaustivamente repetidos, de diferentes modos e em diferentes contextos, e é essa repetição que deve garantir a adesão das mulheres a esta prática.

O Manual de Manejo e promoção do aleitamento materno (1993), sintetiza de forma exemplar os conhecimentos e as recomendações que devem dar sustentação aos processos educativos voltados para profissionais de saúde e mulheres, nas instituições que desejam candidatar-se ao título de Instituição Amiga da Criança, e começa apresentando à equipe de saúde, em linguagem imperativa e pontual, as recomendações atuais para o aleitamento materno (Brasil, 1993, p. 14): amamentar o bebê exclusivamente ao seio durante quatro a seis meses; não lhe dar nenhum líquido ou leite infantil industrializado ou de animais, nos primeiros seis meses; continuar a amamentá-lo até os dois anos ou mais, inserindo quantidades crescentes de alimentos complementares e líquidos oferecidos em xícara. Esclarece que o bebê não deve usar nenhum tipo de chupeta e/ou bico artificial e que

8 Os folhetos citados estão referenciados por número na bibliografia, ao final do texto.

Movimento Porto Alegre, v.9, n. 3, p.33-58, set./dez. de 2003 
a maioria dos recém-nascidos mama de 8 a 12 vezes, em 24 horas, incluindo as mamadas noturnas.

Chama atenção, nesse contexto, tanto a centralidade que a prática do aleitamento e, por extensão, o cuidado com o bebê, deve assumir na vida da mulher-mãe quanto o processo de equalização de tais ensinamentos, que devem interpelar, indistintamente, todas as mulheres, independentemente de sua inserção social e cultural. Deparamo-nos, assim, com recomendações como esta:

A tranquïlidade é indispensável no momento da mamada, que deve ser em local silencioso, confortável e com muita paz, pois, se a mãe estiver ansiosa, pode inibir a descida do leite (folheto 1).

Não é explicado, em nenhuma dessas fontes, como devem proceder os diferentes grupos de mulheres que, por razões diversas, não dispõem desse tempo, de local adequado ou não estejam tranqüilas e nem confortáveis e que, em função de aprendizagens como essa acima citada, provavelmente aumentam ainda mais os níveis de sua ansiedade, visto que sua "incapacidade" em controlá-la "pode interromper a lactação".

Nesse sentido, é interessante considerar que grande parte do esforço despendida com a promoção do aleitamento materno está direcionada para grupos de mulheres trabalhadoras, para as quais a prática do aleitamento, com o grau de disponibilidade física e emocional implícito no regime da livre demanda, fica ainda mais complicada. Tais mulheres - que, no contexto de desemprego estrutural associado ao processo da globalização, estão majoritariamente inseridas no mercado de trabalho informal - são instruídas a "tirar o maior número possível de dias de licença maternidade", a "assegurar-se de que o aleitamento materno está bem estabelecido antes de voltar ao trabalho", além de tirar "manualmente leite de seus seios várias vezes ao dia, para que a pessoa encarregada de ficar com seu bebê possa alimentá-lo com leite usando uma xícara". Recomenda-se, ainda, que "se tiver que ficar separada do bebê por muitas horas no dia, amamente mais à noite [o que] será mais fácil se o bebê dorme com você (folheto 2)".

Movimento Porto Alegre, v.9, n. 3, p.33-58, set./dez. de 2003 
Como e onde estão representadas, nesse discurso, os grupos de mulheres de baixa renda, as com grande número de filhos, as que querem ou precisam inserir-se no mercado de trabalho porque ocupam, crescentemente, a posição de chefes de família ou as que dispõem de acesso precário a redes de apoio social, como creches ou serviços de saúde, ou transporte coletivo, para citar apenas alguns exemplos?

O manual segue descrevendo as vantagens do aleitamento materno exclusivo, no regime de livre demanda, durante seis meses, e complementar até dois anos ou mais, abordando-as a partir dos seguintes focos: a criança, a mãe e a sociedade (Brasil, p. 16-8). As vantagens para a criança são, sem sombra de dúvida, as mais enfatizadas e detalhadas. Trata-se de desdobrar a assertiva de que o leite humano contem todos os nutrientes, em quantidade e qualidade, necessários ao desenvolvimento adequado da criança. Apresentam-se os componentes nutricionais do leite, destacando-se a complexidade dos processos biológicos envolvidos em" sua produção.

Assim, fica-se sabendo que o leite materno não é uniforme e que sua composição muda mês a mês, dia a dia, mamada a mamada e entre o início e o fim da mesma mamada, para satisfazer cada necessidade específica de bebês também específicos. Ou seja, ao contrário dos seres vivos que já podem ser clonados (pelo menos experimentalmente) o leite materno, com estes níveis de complexidade, segue sendo inimitável! Além disso, ele protege o bebê de inúmeras doenças (desde diarréias, infec-ções diversas, raquitismo, alergias, até morte súbita no berço e câncer) porque a mãe lhe transmite, através dele, a sua memória imunológica.

Com relação ao foco vantagens da criança chamam atenção, em especial, alguns acréscimos, deslocamentos e/ou reapropriações importantes no discurso contemporâneo sobre a amamentação. $\mathrm{O}$ primeiro deles, quando enfatiza o papel do leite materno na prevenção dos "males decorrentes da super-alimentação, tão comuns nas comunidade ricas (...) com sérios agravos na adultice, como a obesidade e as intercorrências cardiovasculares" (Almeida; Gomes, 1998, p. 72), permite desarticular a associação entre amamentação, população de baixa renda e desnutrição proteico-energética, que vinha sendo criticada por alguns setores sociais mais engajados. 
O segundo refere-se à informação de que, além de promover um melhor desenvolvimento psicomotor, emocional e social, o consumo do leite materno vem sendo associado com um coeficiente de inteligência mais elevado, o que implica "não apenas a construção de uma geração mais saudável, mas também em uma geração com maior potencial intelectual e, conseqüentemente, há de se esperar que este movimento resulte em um estado nação mais digno no futuro" (Almeida; Gomes, op. cit.). Acerca disso, informa-se às mulheres, pontualmente, que "estudos comprovam que crianças que mamam no peito são mais inteligentes e por isso tem um maior aproveitamento na escola"(!) (folheto 3).

Por último, trata-se de enfatizar, de diversos modos, a centralidade da amamentação para o desenvolvimento emocional saudável da criança:

0 seio é, pois, o primeiro objeto de ligação infantil com a realidade. Criando-se o vínculo inicial a criança incorpora o leite e "sente" a mãe dentro de si. Desta forma, o modo como você oferece o seio pode traduzir-se em segurança e amor. $O$ seu bebê começará a confiar na vida e nas pessoas que o rodeiam (cartilha 1).

O material examinado, exatamente por que se inscreve em discursos que produzem o aleitamento materno como um imperativo, tem pouco espaço reservado à consideração de condições sociais, culturais ou psicológicas que possam impedir ou dificultar a amamentação ou, simplesmente, facultar sua não realização. Em conformidade com a noção de sujeito da racionalidade neoliberal, quase todas as situações são contornáveis desde que haja empenho e vontade da mãe. Por outro lado, existem algumas poucas situações e/ou condições patológicas, a serem definidas e legitimadas como restrições pela autoridade médica, que requerem a suspensão temporária ou definitiva do aleitamento, caso da ingesta de determinados tipos de medicamento (Brasil, 1993, p. 19-20) e das mulheres portadoras do HIV/AIDS, por exemplo. Isso nos coloca, pelo menos, dois tipos de questão.

A primeira é que o valor de verdade de que se revestem os discursos científicos (em especial o médico e o psicológico), que define a relação de linearidade entre amamentação e desenvolvimento físico, cognitivo e emocional da criança, opera, então, como um mecanismo que produz diferentes tipos de crianças -as que foram amamentadas com leite materno e aquelas que não o foram - e de diferentes tipos de mãe - as que amamen-tam, as que não amamentam porque não querem e quelas que 
não amamentam porque não podem. Isso posiciona tanto as mulheres quanto as crianças, de modo diferenciado, nas redes de vigilância e controle instauradas no âmbito dos sistemas de saúde, como sendo crianças e mães normais ou de risco; um posicionamento que tem diferentes efeitos em suas vidas e nas de suas famílias.

A segunda questão é que esse valor de verdade, legitimado pela autoridade que tais discursos instauram, produz, desde essa perspectiva, a culpabilização até mesmo das mulheres que não podem (ou são proibidas de) amamentar, pois elas aprendem -com o que não está dito - que sua incapacidade ou condição interfere no "desenvolvimento saudável" de seu filho.

As vantagens para a mãe, segundo o manual, incluem: a involução uterina e a diminuição do sangramento, desde que o aleitamento seja iniciado na primeira meia hora pós-parto; menor risco de câncer mamário e ovariano; além de vantagens econômicas e redução de carga de trabalho que envolveriam o prepara; manuseio, estocagem e reposição de outros tipos de leite, as quais são bastante enfatizadas também nos folhetos educativos examinados. O pressuposto da economia e da redução de trabalho parece compor um discurso que deve interpelar, de forma mais direta, um determinado tipo de mãe: aquela pertencente às camadas menos privilegiadas da população. Assim, repete-se, de forma exaustiva, que o leite materno "está sempre pronto, em qualquer hora e lugar e na temperatura ideal", que "não precisa ser coado, fervido e nem esfriado" e, sobretudo, que "ele é de graça"(folheto 4).

Três aspectos chamam atenção com relação às vantagens elencadas para a mãe. Em primeiro lugar, a informação de que mulheres nutrizes têm uma elevada eficiência energética, produzindo leite sempre, mesmo com ingesta calórica limitada. Almeida (1999, p.67), ao detalhar a composição do leite materno, acrescenta, também, que a concentração de minerais do leite não é afetada pela dieta da mãe. Em termos práticos isto pode significar que "quando os níveis baixam a patamares que significam situação de maior gravidade, as reservas maternas são literalmente depletadas, chegando em casos extremos, à decomposição de tecidos (...) para manutenção dos níveis de minerais no leite". Ou seja, sob determinadas condições - especialmente naquelas condições de pobreza e desnutrição que imperam em países pobres e nas populações excluídas dos benefí- 
cios da globalização - amamentar pode prejudicar a saúde das mães, um aspecto que jamais vi mencionado em qualquer destes materiais educativos!

A segunda refere-se à constatação de que a ligação afetiva é estimulada, resultando em menos abuso e negligência de crianças, ou seja, o leite materno atua como "elemento agregador, capaz de favorecer a nucleação da família (...) [diminuindo] a ocorrência de violência em núcleos familiares "(Almeida; Gomes, 1998, p. 72). Ainda nessa perspectiva, $\mathrm{o}$ ato de amamentar "oferece à mãe $\mathrm{a}$ chance de demonstrar seu amor" (!)(folheto 5) e "fortalece as mulheres, tornando-as confiantes na sua capacidade de proteger e alimentar seus filhos" (folheto 3). E, por último, temos como mais uma vantagem para a mulher a retomada do pressuposto do efeito contraceptivo da amamentação, desde que esta seja praticada em regime de livre demanda, um pressuposto que havia sido tecnicamente desqualificado com a prescrição maciça dos medicamentos anticoncepcionais a partir da década de 70.

As vantagens para a sociedade são decorrentes, fundamentalmente, de aspectos econômico-financeiros. Informa-se que o custo de uma dieta adequada para a mãe é menor do que a de um bebê alimentado com leites artificiais. Além disso, economiza-se também água e combustível, o tempo gasto com preparo de mamadeiras e visitas ao médico (conseqüentes do maior adoecimento da criança que não mama no seio). Decorre disso uma economia para o Estado em termos de consultas, hospitalizações, exames e medicamentos, além do controle na-r tural das taxas de natalidade. Como enfatiza o Manual: as mães e os bebês ficam mais saudáveis!

Em relação às vantagens para a sociedade, é interessante citar uma das implicações econômico-políticas do aleitamento:

atualmente, estima-se que o Brasil não realiza algo em torno de trezentos milhões de litros de leite humano por ano $_{f}$ em decorrência do desmame precoce (...) considerando os preços praticados na cidade do Rio de Janeiro em março de 1994, a reposição deste volume com leite tipo $C$ demandaria algo em torno de U\$208.000.000. Caso a opção fosse pelo leite em pó de menor custo disponivel no mercado na época, este valor subiria para U\$300.000.000. Este fato torna-se ainda mais grave, ao se considerar que o País não dispõem de uma bacia leiteira com capacidade de suportar quantitativamente esta demanda e nem de um parque industrial, capaz de atender qualitativamente as especificidades que se configuram em decorrência de práticas inapropriadas de desmame. Assim, abrese um importante espaço para as importações e, consequentemente, para a perda de divisas" (Almeida; Gomes, 1998, p.72) . 
Outro aspecto bem interessante de ser examinado no contexto das vantagens para a sociedade é a operação, cada vez mais acentuada, de um discurso que representa a amamentação como uma atitude comprometida com a preservação do meio ambiente: "o aleitamento materno favorece a ecologia, pois sua fonte é natural, renovável e não polui" (folheto 3). Essa afirmação é bastante mais detalhada e ampliada em outro material (folheto 5) onde se aprende, dentre várias coisas, que

O leite materno é completamente seguro ecologicamente; não usá-lo é desperdiçar um recurso valioso. Se todo bebê americano recebesse mamadeira, quase 86 mil toneladas de aluminio seriam usadas nas 550 milhões de latas de leite descartáveis. Caso as latas tivessem etiquetas de papel, deve-se somar outras 1230 toneladas de papel às enormes quantidades de papel brilhante usado na propaganda do produto. (...) Os plásticos [das mamadeiras] representam uma preocupação especial por derivarem do petróleo, serem virtualmente indestrutíveis e permanecerem como poluentes quando jogados fora. (...) Mas, por falar em plásticos, as camadas plásticas dos absorventes femininos não são biodegradáveis. Tendo em vista que a maioria das lactentes não menstruam, quanto mais amamentação, menos poluição (...) Portanto, a mamadeira significa mais desmatamento, mais erosão, mais poluição, mudanças climáticas e desperdício de recursos.

Em um País em que a imprensa noticia, rotineiramente, megavazamentos de petróleo nas águas em que a companhia estatal de petróleo atua ou trafega, não deixa de ser estranha (e, ao mesmo tempo preocupante) esta convocação feita individualmente às mulheres. Mais preocupante, no entanto, é a rede de regulação e controle que parece fechar-se em torno destes corpos, constituindo a mulher-mãe que não amamenta como um sujeito social desviante, ou um sujeito de risco, como quer a literatura médica atual.

Se voltarmos ao manual e ao programa a que ele está vinculado a IHAC - talvez se devesse contemplar, nele, também a dimensão vantagens para o hospital, uma vez que a credencial que beneficia a instituição de saúde só lhe é conferida, pela equipe de avaliação, se for constatada a implementação da prática universal do aleitamento em sua maternidade. O título e as vantagens dele decorrentes dependem, portanto, da produção/instauração de uma cultura de amamentação, na instituição, que insere os corpos de mulheres e crianças no âmbito de um poderoso regime de significação da maternidade. Este regime deve permitir transformar as mulheres em um tipo de mãe que assume o aleitamento exclusivo sob livre demanda, independentemente 
de quaisquer dificuldades ou condições sociais, como expressão fundamental de sua identidade materna.

\section{Um exercício de estranhamento - considerações finais}

Penso que os elementos que apresentei/descrevi são suficientes para os propósitos deste artigo: apontar para uma nova politização da maternidade buscando articulá-la a algumas das condições sócioeconômicas, políticas e culturais contemporâneas que a tornam possível e necessária. Tais aspectos permitem evidenciar o quanto se tornaram complexas, multivariadas e quase que irrefutáveis as vantagens de uma prática apresentada como a mais importante prova do amor e da competência maternas: o aleitamento materno. Nesse contexto de vantagens irrefutáveis, a amamentação e a representação de maternidade a que ela dá sustentação é produzida e passa a funcionar como uma unanimidade capaz de congregar governos, regimes políticos, instituições de ensino e pesquisa, empreendimentos empresariais e econômicos e movimentos sociais que conílituam ou divergem frontalmente nas demais posições que assumem e defendem.

Como se pode ver, também, múltiplos sentidos, que envolvem desde a defesa de uma prática saudável e natural, os direitos das mulheres, a preservação do meio ambiente até a redução da mortalidade infantil e o aumento das divisas do País, confluem, se articulam e conflituam em torno de um determinado modo de exercer a maternidade. Além disso, essa teia discursiva e a trama de poderes que envolve e produz corpos de mulher e de criança, para garantir a adoção do aleitamento, retoma elementos importantes de representações de mãe produzidas nos séculos XVIII e XIX, ao mesmo tempo em que incorpora e ressignifica uma vasta gama de problemas que as sociedades globalizadas produzem e/ou não conseguem resolver, em uma operação que atribui a resolução de tais problemas ao consumo do leite materno e ao exercício de uma dada maternidade.

Valérie Walkerdine (1995, p.211 e seg.), fazendo uma análise histórica da emergência da psicologia infantil no final do séc. XIX, acena para essa compreensão quando discute o posiciona- 
mento da mulher como mãe nesses discursos: por um lado como a estimuladora primária e fundamental do desenvolvimento da autonomia (e da inteligência emocional) da criança e, por outro lado, como culpada por qualquer fracasso individual e/ou social desse futuro adulto. Forna (1999) também alerta sobre os silêncios que se estabelecem em torno do mito da maternidade e desse modo de ser e de sentir que, ao ser definido como divino, científico ou natural, se transforma em argumento inatacável. Em concordância com ela, inscrevo meu trabalho em campos de estudos que historicizam e "localizam", social e culturalmente, as concepções de maternidade com que operamos hoje. No entanto, uma poderosa articulação de saberes e práticas continua funcionando para representá-la como se ela estivesse inscrita em uma essência universal e atemporal de mulher. Diz Forna: Hoje, a criação de filhos ainda é função exclusiva e virtualmente feminina. É também mais difícil que antes. À medida que a quantidade de informações sobre a criação e desenvolvimento dos filhos foi inflando, a maternidade se tornou progressivamente ativa e intervencionista. O trabalho agora começa na concepção. (.4.) Durante a gravidez, o desenvolvimento do bebê e todos os aspectos do comportamento dela são minuciosamente monitorados pelo médico"[e eu diria, pelos profissionais de saúde em geral] (p. 15).

Em que medida estas teorias e estes conhecimentos que produzimos e reproduzimos, em programas como esse aqui analisado, têm contribuído para explicar a violência, a criminalidade, a mortalidade e a morbidade infantil, o aumento dos índices de gravidez na adolescência, a subnutrição, a drogadição, o fracasso escolar, por exemplo, a partir de vínculos inadequados entre mãe/filho, que agora já se estabelecem antes do momento da concepção? Ou através da ausência prolongada da mãe na infância, ou como conseqüência da "dissolução" ou "desestruturação" da família (nuclear moderna) ou, ainda, em função da incapacidade, ignorância ou irresponsabilidade maternas? Que estatuto de maternidade é este que está operando aqui? Com que efeitos? Como profissionais da educação e/ou da saúde, engajadas em estudos de gênero, é esta maternidade que queremos tomar como referência? É esta a única forma desejável de se exercer a maternidade? E seu exercício prende-se a um desejo/capacidade individuais? Em que medida as mães de carne e osso podem, ou querem, reconhecer-se nestas representações? A que custo? Quem está incluído e quem está excluído delas? Quem produz, e como se produzem e se modificam, estas representações de maternidade? Que outros interesses estão em jogo quando se 
produzem definições de maternidade que posicionam o aleitamento como um imperativo irrefutável e inquestionável? Algumas estudiosas não nos deixam esquecer que uma boa parte das teorias que dão suporte a esses campos de conhecimento, bem como a essas políticas e programas, estão inscritas na ciência masculina, branca, heterossexual e cristã, da modernidade ocidental, que as feministas vêm criticando nas últimas décadas.

Do mesmo modo, as (ainda) altas taxas de desmame precoce, tomadas como indicadores para subsidiar a elaboração dos programas de promoção do aleitamento materno, por outro lado, nos obrigam a reconhecer que a amamentação, associada a outros comportamentos e/ou sentimentos apresentados como sinônimo de instinto e/ou competência materna, segue sendo contestada, negada e, sobretudo, impossibilitada no âmbito de nossas sociedades neoliberais globalizadas. Talvez devêssemos começar, pois, por exercitar o estranhamento e a perplexidade e perguntar em nome de quem, de que, como e, sobretudo, com que efeitos, esses sentidos de maternidade têm sido produzidos e implementados.

Ser mãe e amamentar até pode ser muito saudável, desejável e prazeroso para um grande número de mulheres e seus bebês, mas, acreditar nisso não nos autoriza a deixar de visibilizar e problematizar as poderosas redes de disciplinamento e de controle social que, em nome dessa crença, são produzidas e colocadas em circulação nessas pedagogias da maternidade.

\footnotetext{
Educación, salud y modos de inscribir una forma de maternidad en los cuerpos femeninos Resumen: Discuto, en este trabajo, representaciones e identidades de madre que vienen siendo producidas y/ o vehiculadas en eli ámbito de programas de educación en salud dirigidos a la populación materno-infantil. Utilizo ei abordaje de ei análisis cultural, tal como está viene siendo desarrollada por los Estudios Culturales y de Género, para analizar tales programas de salud, concebiéndolos como instancias pedagógicas que producen, resignifican y vehiculan determinados modos de conocer, vivir y valorar la maternidad en la contemporaneidad. Examino modos por los cuales la "pedagogia", engendrada por la tela de discursos y de poderes que instituye tales programas actúa, resignificando la relación madre-hijo para inscribir en ei cuerpo materno en un poderoso regimen de vigilancia y regulación. Tal estratégia de poder incorpora al ejercicio
}

Movimento Porto Alegre, v.9, n. 3, p.33-58, set./dez. de 2003 
de la maternidad atributos relacionados con la resolución de una vasta gama de problemas que as sociedades globalizadas producen y no consiguen resolver. Argumento que en la contemporaneidad se vienen engendrando una nueva politización de la maternidad, en la cual programas de atención a la salud están bastante implicados.

Palabras-clave: Estuúdios Culturales y de Género, Políticas del Cuerpo y Salud, Representación Cultural y Producción de la Maternidad.

Education, health and ways of inscribing a kind of motherhood in feminine bodies Abstract: This paper discusses mother's representation and identities that have been produced and circulate in tiealth education programs addressed to mother-child population. The methodological approach used is cultural analysis, whose theoretical basis is informed by feminist studies and cultural studies, from a post-structuralist perspective. This approach allows to understand health programs as pedagogical instances that produce, re-signify, and circulate certain ways of knowledge, how to live, and also as to value motherhood incontemporary times. The paper also examines ways by which the "pedagogy" engendered by a net of discourses and powers that institute these programs acts. These programs re-signify the mother-child relationship to inseribe the mother's body in a powerful regime of surveillance and regulation. Such strategy of power embodies in motherhood's exercise attributes related to a vast array of problems that globalized societies produce but doesn't know how to solve. The paper also proposes that contemporary times are engendering a new politicization of motherhood, in which health programs have important implications. Keywords: Cultural Studies and Gender Studies, Body and Health's Politics, Cultural Representation, Maternity Production.

Movimento Porto Alegre, v.9, n. 3, p.33-58, set./dez. de 2003 


\section{Referências}

ALMEIDA, José A. Amamentação. Um híbrido natureza-cultura. $2^{\text {a }}$. ed. Rio de Janeiro: Fiocruz, 1999.

ALMEIDA, José A.; GOMES, Romeu. Amamentação: um híbrido natureza-cultura. Rev. Latino Americana de Enfermagem, v. 6, n. 3, 1998: 71-6.

ALVES, J. A. Lindgren. A declaração dos direitos humanos na pós-modernidade. www.pge.sp.gov.br/centrodeestudos/revistaspge/revista5/5rev3.htm, capturado em 06/06/2002.

BEAUVOIR, Simone. O segundo sexo. v. 1 e 2. Rio de Janeiro: Nova Fronteira, 1980.

DEAN, Mitchell. Governamentality - power and rule in Modem Society. Great Britain: Sage Publication, 1999.

DURO, Carmen Motin. Concepções de maternidade e de cuidado infantil de um grupo de mães da Vila Cruzeiro do Sul/POA - RS. Porto Alegre: UFRGS, 2002 Dissertação.(Mestrado em Enfermagem). Escola de Enfermagem, Universidade Federal do Rio Grande do Sul, 2002.

FOR NA, Aminatta. Mãe de todos os mitos: como a sociedade mode/a e reprime as mães - Rio de Janeiro; Ediouro, 1999

HALL, Stuart (ed.) Representation: cultural representatios and signifying practices. London: Sage; Open University, 1997

KLEIN, Carin. "...um cartão [que] mudou a nossa vida"? Maternidades veiculadas/instituídas no Programa Nacional Bolsa Escola. Porto Alegre/RS:UFRGS. Dissertação (Mestrado em Educação). Faculdade de Educação, Universidade Federal do Rio Grande do Sul, 2003.

LAW, Jules. The politics of breastfeeding: assessing risk, dividing labour. Journal of Women in Culture and Society, v.25, n.2, 2000: 407-449.

LOURO, Guacira. Gênero, Sexualidade e Educação: uma perspectiva pós-es-truturalista. Petrópolis: Vozes, 1997.

MARCELLO, Fabiana. Das configurações de um dispositivo: a maternidade como um significante vazio. Porto Alegre: UFRGS, 2002. Proposta de dissertação. (Mestrado em Educação). Faculdade de Educação, Universidade Federal do Rio Grande do Sul, 2002.

MEYER, Dagmar. As mamas como constituintes da maternidade: uma história do passado? Educação \& Realidade, v. 25, n.2, ago/dez 2000a.

MEYER, D.; OLIVEIRA, D. L. Breastfeeding policies and the production of motherhood: a historical-cultural approach. Nursing Inquiry, v.10, n.1, mar. $2003_{ \pm}$

MEYER, D.; OLIVEIRA, D. L. Identidades Traduzidas. Cu/tura e docência teuto-brasi/eiroevangélica no Rio Grande do Sul. Santa Cruz do Sul/RS: EDUNISC; Sinodal, 2000b.

MEYER, D.; OLIVEIRA, D. L. Pedagogías do Aleitamento Materno. Educação, Saúde e produção de identidades de gênero. Porto Alegre: UFRGS/FAPERGS,

Movimento Porto Alegre, v.9, n. 3, p.33-58, set./dez. de 2003 
2002. Relatório de Pesquisa. Faculdade de Educação da UFRGS/Fundação de Amparo à Pesquisa do Estado do Rio Grande do Sul, 2002.

NETTLETON, Sarah. Governing the risky self: how to become healthy, wealthy and wise. In: Petersen, A.; Bunton, R. (eds.). Foucault, Health and Medicine. London: Routledge, 1997.

PETERSEN, Alan. Risk, governance and the new public health. In: Petersen, A.; Bunton, R. (eds.). Foucault, Health and Medicine. London: Routledge, 1997.

SANTOS, Luis Henrique Sachi dos. Biopoliticas de prevenção no Brasil: representações de risco e AIDS nos anúncios televisivos das campanhas de prevenção de massa. Porto Alegre: UFRGS, 2002. Tese de Doutorado. (Doutorado em Educação). Faculdade de Educação, Universidade Federal do Rio Grande do Sul, 2002.

SCAVONE, Lucila. A maternidade e o feminismo: diálogo com as Ciências Sociais. Cadernos Pagu, n. 16, 2001.

SCOTT, Joan. "Prefácio a Gender and politics of History". Cadernos Pagu. Campinas, n. 3, 1994: 11-27.

SILVA, Tomaz T A produção social da identidade e da diferença. In: Silva (org.) Identidade e diferença. A perspectiva dos Estudos Culturais. Petrópolis: Vozes, 2000: 73-102/

SOUZA, Jane" Felipe e cois. Qualificar o cuidado infantil e a cidadania feminina: um trabalho com mulheres atendentes de creches comunitárias em Viamão/RS. Porto Alegre: UFRGS/FAPERGS, 2002. Relatório de pesquisa. Faculdade de Educação da UFRGS, Fundação de Amparo à Pesquisa no Rio Grande do Sul, 2003.

WOODWARD, Kathryn (Ed). Identity and difference. London: Sage \& Open University, 1997.

WALKERDINE, Valerie. O raciocínio em tempos pós-modernos. Educação e Realidade, v. 20, n. 2, jul/dez 1995: 207-26.

ZERO HORA, Caderno principal, edições 25/07/00 e 05/09/00

\section{Fontes empíricas citadas:}

BRASIL (MS/OMS/OPAS/UNICEF) Manual Manejo e promoção do aleitamento materno. Brasília: Unicef, 1993. BRASIL Amamentação on line,

www.aleitamento.org.br/oqueeihac.htm.

Folheto 1 - Aleitamento materno. Entre de peito nessa luta. Secretaria municipal de Saúde de Porto Alegre/RS.

Folheto 2 - Mulher, trabalho e amamentação; todos saem ganhando. Prefeitura Municipal de Porto Alegre/RS

Folheto 3 - Semana Mundial de amamentação. Centro de Saúde Murialdo; Hospital Moinhos de Vento. Porto Alegre/RS.

Movimento Porto Alegre, v.9, n. 3, p.33-58, set./dez. de 2003 


\section{Recebido em: 16/10/2003}

Aprovado em: 22/11/2003

Dagmar Estermann Meyer Rua Carlos von Koseritz, 564/401

Porto Alegre- RS

90540-030

esterman.ez@brturbo.com

Movimento Porto Alegre, v.9, n. 3, p.33-58, set./dez. de 2003 